\title{
A Evolução das Configurações Produtivas Locais no Brasil: Uma Revisão da Literatura
}

- Lia HASENCLEVER*
- ISLEIDE ZISSIMOS**

\begin{abstract}
RESUMO
A desconcentração industrial, vivenciada pelo Brasil entre os anos 1970 e 2000, foi acompanhada pelo surgimento de novas configurações produtivas locais, consolidação de antigas, especialmente em relação ao tamanho e à organização das empresas, e mudanças no perfil empresarial. Esse fenômeno tornou-se objeto de estudo de diversos grupos de pesquisa. $O$ objetivo deste trabalho é analisar criticamente esses estudos sobre o Brasil e a forma como os grupos de pesquisa tomaram emprestado definições e modelos das diferentes escolas e programas de pesquisa fundados em contextos diferentes da realidade brasileira. Em geral, observou-se que os estudos sobre desenvolvimento econômico local têm avançado em relação às metodologias quantitativas de identificação das especializações setoriais. Contudo, não há consenso entre os diferentes grupos de pesquisa sobre as metodologias mais apropriadas para a realidade brasileira. Falta ainda avançar nos métodos de mensuração e identificação da densidade das redes de empresas e de seus aspectos qualitativos.
\end{abstract}

\section{PalavRAS-CHAVE}

desenvolvimento econômico local, configurações produtivas locais, metodologia quantitativa, metodologia qualitativa

\section{AbSTraCT}

The Brazilian industrial structure went trough a process of decentralisation between 1970 and 2000 . New industrial clusters emerged, followed by changes in entrepreneurial profile and, particularly, in the size of firms and their organisation. The objective of this paper is to analyse critically various studies of local development that were undertaken by Brazilian and foreign research groups. We examine how those groups interpret and apply concepts and research agendas developed previously. We find that the quantitative methodologies used to identify specialised sectors are evolving. But there is no consensus among researchers about the appropriate methodology and statistical sources for the study of Brazil. It is still necessary to develop methodologies that evaluate the density of links among firms and their qualitative aspects.

\section{KEY WORDS}

local development, industrial decentralization, quantitative methodology, qualitative methodology

\section{JEL CLASSIFICATION \\ $018,054, R I I$}

+ Uma versão inicial deste artigo foi preparada para o Seminário Internacional Los Espacios de la Globalizacion. Mutaciones, Articulaciones, Interaciones, organizado pelo CIESAS, Universidade de Guanajuato, IRD e CEMCA, no México, em junho de 2004. Para a presente versão as autoras agradecem os comentários do parecerista anônimo, responsabilizando-se por eventuais incongruências remanescentes.

* Professora Doutora do Instituto de Economia, da Universidade Federal do Rio de Janeiro. Endereço: Av. Pasteur, 250, sala 130, CEP 22290-240. Rio de Janeiro, RJ, Brasil. Email: lia@ie.ufrj.br.

* Aluna de doutorado do Instituto de Economia, da Universidade Federal do Rio de Janeiro, Brasil. E-mail: imaeda@nuca.ie.ufrj.br.

(Recebido em outubro de 2004. Aceito para publicação em fevereiro de 2006). 


\section{INTRODUÇÃO}

O estudo do desenvolvimento econômico local enfrenta vários desafios, todos condizentes com a complexidade intelectual deste tema. Ele não só reúne diversos campos do conhecimento, tais como a economia, a sociologia e a política, como também a ênfase na escala local nas áreas de conhecimento crescimento e desenvolvimento econômico é recente. De fato, até os anos 1980 consideravam-se os fenômenos do crescimento e do desenvolvimento essencialmente fenômenos de escala macroeconômica. Eram tratados à escala nacional e mundial em vez de local (territorial) e empresarial.

Uma infinidade de razões, desde as histórico-institucionais até as teórico-abstratas, pode ser apontada para a relevância do novo enfoque local e empresarial no estudo

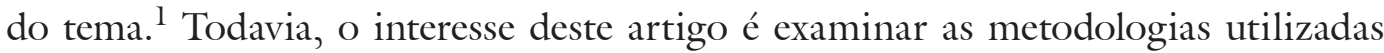
nos estudos sobre o Brasil realizados pelos diferentes grupos de pesquisa brasileiros e estrangeiros. $\mathrm{O}$ foco da análise está na forma como estes grupos tomaram emprestado conceitos e definiçóes das diferentes escolas e programas de pesquisa que foram fundados em contextos diferentes da realidade brasileira. Nossa motivação principal é que somente a análise de forma crítica e comparada das diferentes proposições metodológicas e empíricas já realizadas sobre o enfoque local e empresarial é capaz de permitir o avanço do conhecimento no tema.

O estudo do desenvolvimento econômico local é um tema novo e complexo, com muito mais conhecimento acumulado em experiências históricas que se apresentaram na Europa, nos Estados Unidos, e nos países de industrialização recente, conhecidos como NICs (Newly Industrialized Countries). Contudo, em relação ao Brasil, nos parece mais adequada a realização de estudos exploratórios que "façam emergir a realidade" subjacente às transformações econômicas observadas nas últimas décadas, buscando a construção de taxonomias baseadas nos principais fatos estilizados observados do que trabalhar com conceitos e definições que emergiram de realidades diferenciadas econômica, social e politicamente. (Fauré e Hasenclever, 2003).

Os princípios utilizados para direcionar nossa análise crítica são (i) não adotar um posicionamento metodológico particular e; (ii) não construir uma realidade a priori por meio de categorias teóricas analíticas bem definidas. O uso desses princípios nos parece um procedimento mais apropriado na realização de estudos em que o conhecimento seja mais maduro e consolidado, tanto conceitual quanto empiricamente. Este certamente ainda não é o caso do desenvolvimento econômico local.

1 Ver Fauré e Hasenclever (2003), e Carlsson e Eliasson (2003), respectivamente sobre as razões histórico-institucionais brasileiras e sobre o enfoque teórico-abstrato. 
Esta análise crítica também permite a recuperação, ainda que implicitamente, do debate em torno das transformações radicais da realidade industrial anterior tão bem estilizada pelo modelo de produção fordista e a tentativa de explicar a emergência de novas configurações produtivas por meio do modelo de produção flexível. De fato, cabe questionar: em que medida o modelo de regime de produção flexível em substituição ao regime de produção fordista captura a realidade das aglomerações brasileiras? Ou seria o modelo de distrito industrial melhor para capturar esta realidade? Há uma convergência entre os resultados observados pelos diferentes estudos realizados ou quais são as principais diferenças e por que elas existem?

O objetivo deste artigo é comparar e analisar criticamente vários estudos de caso realizados no Brasil sobre o desenvolvimento econômico local. A ênfase recairá nos conceitos múltiplos e nas definições utilizadas por diversos autores e as opções metodológicas realizadas por grupos de pesquisa brasileiros e estrangeiros estudando o Brasil, relativos a clusters, distritos industriais, sistemas produtivos locais etc. Será dada ênfase ao enfoque amplo e múltiplo elegido por esses grupos e às dificuldades que isso traz para o estabelecimento de comparações entre os vários estudos empíricos já realizados e, portanto, para o avanço do conhecimento. Um outro aspecto derivado destas escolhas metodológicas e que também será objeto de análise são as escalas de observação (geográfica, de produção etc.), os instrumentos de coleta de dados primários e sua sistematização e organização, as fontes secundárias dos dados utilizados e as taxonomias construídas.

Organizamos o artigo em cinco seções, além desta introdução. Na próxima seção são identificados os principais conceitos e definições utilizados em estudos sobre o Brasil, apontando os seus elementos relevantes e discutindo seus pontos fortes e fracos. $\mathrm{Na}$ segunda são destacados modelos aplicados ao Brasil e suas filiações às escolas e conceitos disponíveis na literatura européia e americana. A terceira seção é dividida em duas partes. Na primeira são apresentados métodos quantitativos de identificação de aglomerações. Na segunda, são discutidas algumas bases de dados secundárias utilizadas nos métodos quantitativos e suas limitações. Na quarta seção são apresentadas algumas formas de classificar as configuraçóes identificadas que podem ser objetos de políticas econômicas. Na última seção são tecidos comentários finais sobre as semelhanças e diferenças entre as várias escolhas metodológicas dos estudos, emitidas críticas sobre as dificuldades de sua compatibilidade e comparação e sobre o estado da arte do conhecimento no Brasil. 


\section{PRINCIPAIS ESTUDOS DE DESENVOLVIMENTO ECONÔMICO LOCAL: TERMOS E DEFINIÇÕES}

As aglomerações espaciais de empresas, a especialização industrial local e o desenvolvimento local têm sido estudados por vários autores que utilizam termos e definiçôes distintos. Alguns desses termos e definições evocam os modelos de distritos industriais; outros, os modelos de cluster (por exemplo Schmtiz, 1995, e Vargas, 2001); outros, os sistemas produtivos localizados (por exemplo, Suzigan et al., 2003); sistemas industriais localizados (Galvão, 1999); complexos industriais ou de industrialização descentralizada (Raud, 1999 e Tironi, 2001), de comunidades industriais (Bazan e Schmitz, 1997), de arranjos produtivos e inovativos locais (Cassiolato e Lastres, 2003). Ainda há autores que apenas procuram entender os aspectos relevantes para a competitividade das micro e pequenas empresas (Lins, 2000). Finalmente, Fauré e Hasenclever (2003) propõem o uso do termo configuração produtiva local (CPL) de forma a não identificar a priori o tipo de fatos estilizados que seriam encontrados no estudo das especializações produtivas localizadas no Estado do Rio de Janeiro.

Todos esses termos procuram traduzir formas de concentração de empresas e instituições num território e a natureza de suas atividades, bem como o grau de interação entre esses agentes. Eles foram adotados de acordo com as diferentes propostas analíticas dos vários pesquisadores a partir de estudos de outras realidades que não a brasileira. Neste sentido, vários destes termos podem evocar a priori realidades históricas completamente distintas. Além disso, é importante observar que esta miríade de termos causa confusão por dois motivos: (i) o mesmo objeto pode ser designado por diferentes termos. Por exemplo, a região do Vale dos Sinos (RS) é denominada ao mesmo tempo de arranjo produtivo local (Cassiolato e Lastres, 2003) e cluster (Schmitz, 1995); e (ii) diferentes termos são usados como sinônimos. Por exemplo, Crocco et al. (2003) utilizam tanto sistema produtivo local como cluster para designar a mesma concentração territorial de empresas.

Essa variedade de termos reflete a dificuldade que existe para se definir com precisão o fenômeno que está sendo estudado. As definições apresentam, em geral, diversas possibilidades de interpretação, principalmente devido à falta de delimitação sobre os elementos que procuram descrever. Por exemplo, a definição de arranjo produtivo local (APL), que é provavelmente a noção mais difundida nos organismos governamentais e algumas universidades brasileiras, é:

"aglomeraçôes territoriais de agentes econômicos, politicos e sociais - com foco em um conjunto especifico de atividades econômicas - que apresentam vinculos mesmo que incipientes." (Cassiolato e Lastres, 2003, p. 11). 
O conceito de APL é aberto o suficiente para abranger qualquer tipo de indústria ou especialização. Não aponta para a intensidade das especializações das empresas, para as atividades que estão sendo incluídas e nem para a abrangência geográfica onde as empresas estão operando. Cassiolato e Lastres (2003) reconhecem esse fato:

"O argumento básico do conceito adotado pela Rede é que onde houver produção de qualquer bem ou serviço haverá sempre um arranjo em torno da mesma (...) Tais arranjos variarão desde aqueles mais rudimentares àqueles mais complexos e articulados. Desta forma consideramos que o numero de arranjos produtivos locais existentes no Brasil seja tão grande quanto a capacidade produtiva nacional permita."

Contudo, é possível apontar, de maneira geral, os elementos principais nas definições propostas para os estudos de desenvolvimento econômico local e a concentração de atividades. Eles são normalmente espaços geográficos definidos onde estão localizados os agentes, instituições e as empresas de alguma forma interligadas entre si e com as instituições.

Em relação à escala territorial, as definições não costumam fazer referência a qualquer fronteira física ou política e deixam para a dimensão econômica a demarcação do território de abrangência da concentração de empresas. Este princípio parece apropriado, já que a concentração de empresas pode ultrapassar o espaço limitado por uma fronteira política, como uma cidade, ou por uma fronteira física, como um rio, assim como pode ser menor que o espaço limitado pelas mesmas fronteiras. No entanto, a ligação entre os âmbitos territorial e econômico é enfraquecida, pois nenhuma associação é feita entre o espaço ocupado pela concentração de empresas e a presença e escala de economias externas ou aprendizado coletivo. (Martin e Sunley, 2003).

As instituiçõoes são incluídas na maioria das definições de concentração de empresas. Elas podem assumir as mais variadas formas e funções. Podem ser governamentais, não-governamentais, mistas, privadas, de pesquisa, universidades, sindicatos etc. As definiçõoes não indicam quais instituições devem ser incluídas. Suzigan et al. (2003), por exemplo, as descrevem como "instituições locais de apoio às empresas". Galvão (1999) detalha um pouco mais:

"densidade institucional baseada na presença de uma rede de informações e de produção entre as empresas, representada por organizações de trabalbadores ou sindicatos; associações e grupos comunitários de inte-

2 Referem-se à Rede de Pesquisa em Sistemas Produtivos e Inovativos Locais, Redesist, da Universidade Federal do Rio de Janeiro. 
resses especificos; autoridades regionais ou locais; e instituiçôes de apoio especializado ou de serviços." (Galvão, 1999, p. 7).

Em outros estudos sobre o Brasil destacam-se, em geral, as instituiçôes consideradas envolvidas na promoção do desenvolvimento das empresas. Fauré e Hasenclever (2005), por exemplo, avaliam no Rio de Janeiro a atuação de organismos como o Serviço Brasileiro de Apoio às Micro e Pequenas Empresas (Sebrae) e o Sistema Firjan - Federação das Indústrias do Estado do Rio de Janeiro; Centro Industrial do Rio de Janeiro (CIRJ); Serviço Social da Indústria (SESI); e Serviço Nacional de Aprendizagem Industrial (SENAI). Estes autores incluem também o estudo das administraçôes municipais e os seus projetos de apoio ao desenvolvimento, bem como aqueles projetos de outras instâncias administrativas federais, estaduais, e internacionais, tais como o Banco Interamericano de Desenvolvimento e a Câmara de Comércio de Milão.

É importante que junto com as instituições dedicadas ao desenvolvimento, instituições mais tradicionais, como a empresa e o mercado de trabalho, bem como as suas instituições, tais como os sindicatos trabalhistas, também sejam investigados. Em vários estudos estas instituições não são incluídas. Outra constatação é que os estudos apresentam discussões breves sobre as questões de coordenação entre as instituições e entre as instituições e as empresas. Apenas a cooperação - tipo particular de coordenação bastante explorado na literatura ${ }^{3}$ - é abordada nesses estudos. Mas os problemas que dificultam a cooperação, tais como os de informação assimétrica e de comportamento oportunista, que poderiam contribuir para o entendimento de como as instituições brasileiras seriam capazes de facilitar a cooperação entre empresas, ainda não foram tratados com profundidade. Além de interesses não coordenados, problemas relacionados às crenças incompletas, incorretas ou diferentes de agentes sobre outros agentes ou o conhecimento divergente sobre métodos e processos produtivos também foram pouco explorados até agora.

Em relação às empresas, as definições não estabelecem critérios quanto ao seu grau de especialização ou sua densidade no espaço ou extensão de setores e atividades que devem estar sendo incluídos. Também não há especificaçóes padronizadas sobre o tamanho dessas empresas. No Brasil, entretanto, há uma tendência de se enfatizar as pequenas e médias empresas (PMEs). O argumento é que estas teriam vantagens sobre as grandes empresas quando localizadas proximamente por poderem responder mais rapidamente às mudanças ambientais repentinas.

O fato de as PMEs estarem localizadas proximamente permitiria que elas se apropriassem das economias externas geradas pela complementaridade e facilidade de transações

3 Ver, por exemplo, Putnam (1993). 
entre as fábricas e o aumento da divisão técnica do trabalho, resultantes das vantagens do contato direto, troca de informações, articulações estratégicas, fluxos de mercadorias e trabalho. Estas economias externas e a maior flexibilidade das PMEs juntas seriam capazes de compensar com vantagens as grandes empresas verticalizadas do padrão de produção fordista. Dentro desta perspectiva encontram-se Piore e Sabel (1984), Scott (1988) e Storper (1989), todos autores com importantes contribuições no desenho do modelo flexível de produção como modelo alternativo ao modelo de produção fordista.

No entanto, deve-se considerar que embora algumas configurações brasileiras sejam relativamente desenvolvidas, muitas ainda estão próximas das chamadas "aglomerações de sobrevivência”. (Altenburg e Meyer-Stamer, 1999). As empresas nestas configurações são justamente as de menor porte, têm características informais e produzem bens e serviços de baixa qualidade para mercados locais. Os graus de especialização e de cooperação também são baixos, assim como os salários pagos aos trabalhadores.

O aparente desempenho ampliado dessas configuraçóes é comumente atribuído mais aos efeitos de aglomeração, de concentração espacial, de economias de aprendizagem e de densidade das redes do que às características inerentes das PMEs. O foco dos estudos nos fatores externos às PMEs pode estar deixando descoberta uma análise mais completa ou a análise sobre a importância da organização interna das empresas para o estudo de seu desempenho. Talvez a flexibilidade e a capacidade de se adaptar aos choques exógenos sejam, na realidade, originários das rotinas intrínsecas das empresas. Por isto, antes de se fazer qualquer afirmação sobre o desenvolvimento e o desempenho potencial desses agentes, tanto os fatores internos como os externos às empresas devem ser investigados mais cuidadosamente.

O tipo de relações entre os agentes talvez seja o aspecto mais obscuro das definições envolvendo aglomeraçóes territoriais. Estas relaçóes podem ocorrer tanto no mercado como fora do mercado. As definições também não estabelecem qualquer critério sobre a densidade ou freqüência das relações, os spillovers de conhecimento, os vínculos formais e informais entre as firmas, a rivalidade, as redes sociais e de negócios etc. Além disso, os estudos não costumam explorar a origem dessas relações, tomando elas como dadas. Por exemplo, não consideram que algumas delas podem surgir de riscos inicialmente assumidos pelos empresários ou de contratos habituais entre firmas.

Apesar das imprecisóes observadas nos termos e definições, vários modelos foram adotados. Na próxima seção serão vistos os principais modelos aplicados ao estudo do fenômeno no Brasil. 


\section{DESENVOLVIMENTO ECONÔMICO LOCAL BRASILEIRO E ESTUDOS RE- ALIZADOS}

O primeiro esforço de análise sistemática de desenvolvimento econômico local e aglomerações espaciais de empresas em países em desenvolvimento foi feito por Schmitz (1982). Sua análise é centrada nas empresas de menor porte e suas restrições internas e externas, dificuldades enfrentadas e potencial para expansão. Ainda no contexto de desenvolvimento econômico, o autor introduziu o conceito de eficiência coletiva, definido como as "vantagens competitivas originárias de economias externas e ação conjunta." (Schmitz e Nadvi, 1999, p. 1504). Mais recentemente ele estudou a região do Vale dos Sinos, no sul do Brasil (Schmitz, 1995), procurando averiguar as características do modelo de distritos industriais italianos presentes nessa região, tais como presença de empresas de menor porte, ação coletiva e exportação. Assim como Schmitz (1995), vários autores estudando países em desenvolvimento, inspirados nas "histórias de sucesso" da Itália, também voltaram sua atenção para os elementos desse modelo.

O termo distrito industrial apareceu originalmente em Marshall (1920), ao estudar as aglomerações de empresas da Inglaterra do final do século XIX. O conceito de economias externas surge a partir da observação de Marshall de que a concentração espacial de firmas pode prover ao conjunto de produtores certas vantagens competitivas que não seriam verificadas caso eles estivessem atuando em regiões distantes umas das outras. Além disso, Marshall destaca o papel dos trabalhadores como disseminadores de informação e experiência, dentro do distrito, e dá importância tanto para as relações comerciais como para aspectos socioculturais.

Utilizando as idéias de Marshall, Becattini (1979) atualiza a definição de distrito industrial, ao pesquisar a experiência italiana, que passa a envolver a "presença ativa de uma comunidade de pessoas e uma população de firmas numa área limitada pela história ou pela natureza." A população de firmas é formada por grupos de firmas especializadas trabalhando em conjunto de forma complementar. A comunidade de pessoas abrange indivíduos que dividem uma identidade comum ou sentimento de pertencimento a um determinado grupo e um sistema de valores e crenças que moldam o comportamento individual.

A escala de análise está situada entre o setor e a empresa. Do ponto de vista técnicoeconômico há ênfase na especialização de empresas de menor porte em diferentes fases do mesmo processo produtivo. Assim, as economias tradicionalmente auferidas por empresas de maior porte também passam a ser acessadas por empresas de menor porte, instaladas na mesma localidade, e são chamadas pelo termo marshalliano de "economias externas". Do ponto de vista socioeconômico ele mostra como indivídu- 
os de determinadas comunidades que possuem habilidades específicas transferem o conhecimento e a tecnologia dentro dos distritos industriais.

A utilização do modelo de distritos industriais em análise de aglomerações de empresas vem da dificuldade de construção de uma teoria universal capaz de abranger o surgimento, a dinâmica e a evolução dessas configuraçóes e ao mesmo tempo dar conta de incorporar as inúmeras formas que elas podem assumir. Em particular, o modelo de distritos industriais é compatível com um debate mais recente sobre a importância de empresas de menor porte em países em desenvolvimento, em particular no Brasil, como já mencionado, e do seu potencial para competir em mercados globais. A partir desse debate, uma nova agenda de pesquisa foi colocada para esses países consistindo em: (i) detectar aglomerações semelhantes às da Itália; e (ii) averiguar as condições que estimulam, modificam ou inibem seu crescimento. (Schmitz e Nadvi, 1999).

Alguns seguidores da tradição italiana nos estudos sobre o Brasil concentram-se no primeiro item dessa agenda, procurando as características presentes, ou discutem os aspectos ausentes do modelo de distritos industriais em aglomeraçóes de empresas por meio de estudos empíricos. Galvão (1999) faz esse exercício no Vale do Paranhana, no sul do Brasil, e Lins (2000) faz o mesmo para o Médio Vale do Itajaí.

Outros autores, mais interessados no segundo item da agenda, têm perspectiva evolucionária, mas ainda seguindo a tradição italiana tentam identificar e classificar as inúmeras formas, diferenciadas ou mesmo "híbridas", de distrito industrial. No entanto, eles preferem usar a definição um pouco mais frouxa de sistema local de produção (SLP) (Belussi e Gottardi, 2000) em vez de distrito industrial, já que este último é comumente entendido como específico para o nordeste da Itália. A função do conceito SLP é também a inclusão de outros modelos de desenvolvimento econômico local. Suzigan et al. (2003) utilizam essa abordagem ao estudar aglomerações de empresas no Estado de São Paulo com a intenção de apontar quais delas podem ser objeto de ações de apoio e medidas de políticas públicas.

Uma linha de pesquisa mais recente, também resultante do modelo de distritos industriais e bastante aceita nos estudos sobre Brasil, é a análise do crescimento econômico como fortemente dependente do conhecimento assim como dos outros fatores de produção tradicionais, como capital, trabalho e terra.

Nessa abordagem o conhecimento é compreendido como informação estruturada e interpretada. É comumente classificado em dois tipos: codificado e tácito. Stevens (1998) descreve o conhecimento codificado como aquele que pode ser reduzido à in- 
formação (know-what, know-why), enquanto o conhecimento tácito inclui capacitações, como criatividade e discernimento (know-how, know-who).

A introdução do conhecimento em bens e serviços gera inovações. A inovação, por sua vez, é considerada elemento importante de competitividade dinâmica e sustentável. A capacidade das empresas absorver e gerar tais inovaçôes vem do aprendizado de novos conhecimentos. Esse processo é acelerado pelo aumento da eficiência das novas tecnologias de informação e comunicação.

Faz sentido pensar que a aglomeração territorial de agentes pode favorecer a economia baseada no conhecimento. Enquanto o conhecimento codificado é relativamente fácil de adquirir ou ser transferido, o conhecimento tácito é difícil para descrever e os agentes comumente não têm consciência de possuí-lo. Assume-se então que o conhecimento tácito é adquirido por meio de exemplos ou de experiência direta. Se a hipótese utilizada for a de que o conhecimento tácito é mais bem transmitido e adquirido por meio do contato face a face entre agentes que dividem similaridades, tal tipo de conhecimento tende a ser localizado. Logo, ele pode servir de base para um nível diferenciado de inovação ou ser útil em situações de mudança repentina de cenário econômico e, neste caso, a proximidade geográfica importa. ${ }^{4}$

Num ambiente de concorrência globalizada produtiva e financeiramente e sem barreiras tarifárias, a competitividade das empresas pode depender de processos localizados de criação de conhecimento e aprendizado coletivo. Estes elementos são entendidos como de natureza interativa e incorporados em pessoas, organizações e relacionamentos e influenciados pelo território localizado. (Crocco et al., 2003). Os agentes das aglomerações, por estarem localizados proximamente, podem se beneficiar de externalidades dentro e fora do mercado onde atuam, que podem ser fontes de inovações e aumento de produtividade. Esta abordagem é utilizada por Santos et al. (2002) num estudo de caso sobre as aglomerações industriais de calçados de Nova Serrana e da rede de fornecedores Fiat. De acordo com os autores:

\section{"os elementos tácitos constituem o múcleo do conbecimento individual e coletivo. (...) Parte importante do processo inovativo é, portanto, de na- tureza essencialmente localizada."}

Ainda não há evidência sobre como um dado tipo de conhecimento está vinculado a uma certa configuração geográfica de empresas, como arranjos, sistemas e redes, ou a qualquer forma específica de relação social. Também não há evidência sobre a maneira como interfere no sucesso dos negócios das empresas ou se manifesta como fonte de vantagem competitiva. Embora o conhecimento codificado seja passível de

4 Ver Gentler (2003) para mais detalhes. 
mensuração, a forma como o conhecimento tácito se expressa ainda é de difícil apreensão e quantificação, deixando uma proporção do total do conhecimento incógnita. Nos estudos sobre o Brasil, estas dificuldades não são tratadas pelos pesquisadores que utilizam o enfoque da economia baseada no conhecimento. Na prática de campo eles assumem que ambos os tipos de conhecimento são inerentes às aglomerações de empresas, e tais tipos acabam aparecendo implicitamente ou indiretamente nos estudos empíricos com foco na inovação de produto ou processo não realizando ou apresentando esforços metodológicos para capturar o conhecimento tácito.

Mais recentemente, nos estudos sobre o Brasil, vêm surgindo algumas discussões sobre a abordagem de redes sociais e de capital social. Nesta abordagem o foco estaria na comunidade de pessoas oriunda da definição de distrito industrial de Becattini (1990). A idéia básica é que além dos fatores técnico-produtivos, os fatores extraeconômicos também teriam influência no processo de tomada de decisão econômica. Granovetter (1985) originalmente apresenta essa noção ao definir o conceito de social embeddedness. O autor argumenta que a decisão econômica não é necessariamente produto da racionalidade individual pura, podendo haver fatores sociais, culturais ou políticos por trás dessas decisões.

Contudo, as contribuições mais influentes sobre os trabalhos contemporâneos pesquisando capital social diretamente foram dadas por Bourdieu (1986), Coleman (1990) e Putnam (1993). Bourdieu (1986) fornece uma definição sociológica de capital social, que inclui um conjunto de recursos atuais ou potenciais, ligado à posse de uma rede durável de relações institucionalizadas, por meio do conhecimento e reconhecimento mútuos. Para Coleman (1990), que tem pesquisa no campo da educação para os adolescentes, capital social é de natureza microeconômica e pode ser definido como um conjunto de recursos que facilita ações dos indivíduos que estão em uma estrutura social.

Putnam (1993) apresenta uma definição que valoriza mais a visão institucional/holística. Explicitamente valoriza a coletividade e a solidariedade. Para ele o capital social diz respeito a características da organização social, como confiança, normas e sistemas que contribuam para aumentar a eficiência da sociedade e facilitem as ações coordenadas. Logo, o capital social é capaz de melhorar o bem-estar e facilitar as relações e iniciativas dos agentes. Além disso, quanto mais elevado o nível de confiança numa comunidade, maior a probabilidade de haver cooperação.

O capital social é comumente mencionado nos estudos de caso. Embora o conceito e a teoria sejam bem claros e desenvolvidos, a maior parte dos estudos não aponta suas filiações. É citado como elemento importante para facilitar a cooperação quando, na verdade, a noção deste é mais ampla e complexa, sendo pouco explorada nos estudos. 
Existe, entretanto, um consenso entre os autores sobre a importância das instituições intermediárias, como associações de caráter cívico, organismos públicos e privados de apoio às empresas, a Igreja, a escola etc. como instrumentos catalisadores do desenvolvimento das PMEs. Um estudo formal com foco sobre o capital social numa configuração produtiva localizada na cidade de Itaguaí (RJ) foi feito por Muls (2004).

Uma das formas de averiguar a presença de capital social é mediante a análise de redes sociais. Essa técnica permite que o comportamento individual seja associado à estrutura social à qual ele pertence. Os instrumentos utilizados podem ser teoria dos grafos ou análise matricial. No entanto, em estudos sobre o Brasil essas técnicas ainda não foram utilizadas no contexto de aglomerações de empresas. Mas existe uma revisão da literatura sobre esse assunto, que pode ser encontrada em Marteleto e Silva (2004) em que os autores sugerem sua aplicação em arranjos produtivos locais brasileiros para estudos sobre desenvolvimento. Contudo, a mensuração do capital social não é trivial devido à natureza multidimensional de suas definições e às transformações ao longo do tempo das organizações informais e das instituições formais.

Existem ainda os autores que não explicitam sua filiação teórica, mas as questões da especialização, da flexibilidade e da concentração espacial estão presentes nos seus trabalhos sobre aglomerações industriais no Brasil. As questões da coordenação, cooperação, eficiência coletiva, concorrência dentro dessas aglomerações são aspectos, por sua vez, importantes para identificar sinergias e desempenho em linhas de abordagem tanto teóricas, quanto empíricas. De acordo com Fauré e Hasenclever (2005), que trabalharam com a noção de configuração produtiva local (CPL), as vantagens de recorrer a esta noção de CPL são: (i) não antecipar o nível de cooperação entre as empresas; (ii) não antecipar o grau de especialização e; (iii) esta abordagem é mais adequada ao contexto econômico brasileiro em que conjuntos de PMEs constituem a base produtiva de muitas cidades e muitas microrregiões econômicas.

Nas próximas duas seções serão mostrados os métodos de identificação e classificação de aglomerações de empresas aplicadas ao Brasil.

\section{MÉTODOS DE IDENTIFICAÇÃO E CLASSIFICAÇÃO UTILIZADOS NOS ESTUDOS SOBRE DESENVOLVIMENTO ECONOOMICO LOCAL}

De maneira geral, os métodos de identificação de aglomeraçóes de empresa aplicados ao Brasil podem ser agrupados em três abordagens básicas. A primeira diz respeito ao fenômeno da desconcentração espacial que procura traçar um quadro abrangente da evolução da distribuição espacial da indústria. São estudos de natureza top-down. A idéia desses estudos é indicar as grandes tendências da localização dos diferentes 
setores das indústrias, sem aprofundar a investigação sobre aglomerações de empresas de menor porte. Essa investigação é um dos objetivos de uma segunda abordagem conhecida como industry perception method (IPM), provavelmente a metodologia mais difundida no Brasil até o presente momento. Vários desses estudos são de natureza bottom-up quando procuram identificar e caracterizar configurações numa área particular. A terceira abordagem, ainda em estágio inicial, mas que deve se estabelecer rapidamente, é um aprimoramento e sofisticação dos estudos sobre a primeira abordagem de desconcentração industrial. Esses estudos envolvem índices de concentração industrial modificados, análise multivariada e aplicação de modelos econométricos. Breves descrições e alguns exemplos dos três tipos de abordagem são apresentados a seguir.

Os primeiros estudos de caráter quantitativo realizados no Brasil, relacionados à identificação de aglomerações espaciais de empresas, apareceram na década de 1990 e tinham a análise centrada no fenômeno da desconcentração industrial. A desconcentração industrial é referida basicamente como a perda da importância relativa da indústria em regiões do Brasil, tradicionais neste setor, e o surgimento de novas áreas de rápido crescimento industrial. Alguns estudos interessantes sobre a desconcentração industrial são feitos por Diniz e Crocco (1996), Pacheco (1999) e Saboia (2000). ${ }^{5}$

Diniz e Crocco (1996) utilizam uma metodologia baseada na análise da participação no emprego e da produção industrial para avaliar a distribuição espacial da indústria em três pontos no tempo: 1970, 1980, 1991. As áreas industriais relevantes (AIRs) são microrregiões homogêneas, definidas pelo Instituto Brasileiro de Geografia e Estatística (IBGE), que obedecem o critério de ter mais de 10.000 pessoas empregadas na indústria. Um dos principais resultados do estudo foi a constatação de que novas AIRs surgiram em todas as regiões do País desde 1970. Essas áreas podem ser ordenadas de acordo com suas taxas de crescimento. Os autores sugerem que as AIRs com as maiores taxas devem ser investigadas mais profundamente. Eles também sugerem que as regiões emergentes podem se enquadrar na taxonomia desenvolvida por Markusen (1994) apresentada mais adiante.

Assim como Diniz e Crocco (1996), Pacheco (1999) tem como ponto de partida a participação da produção industrial e estende a análise para gêneros segundo a natureza predominante da demanda final. Ele constata que entre 1970 e 1985 o processo de desconcentração da indústria envolveu praticamente todos os seus segmentos. O autor especula que a nova distribuição espacial da indústria pode acentuar a heterogeneidade interna das regiões e pode vir acompanhada pelo surgimento de novas "ilhas de produtividade", crescimento das antigas periferias e aumento da importância relativa das cidades médias.

5 Andrade e Serra (2001) também utilizam essa abordagem. 
Saboia (2000) também estuda o fenômeno via análise da dinâmica do emprego durante a década de 1990 entre regióes e setores da indústria de transformação e extrativa mineral. Ele constata que há deslocamento do emprego industrial da região Sudeste para o Sul, Centro-Oeste e Nordeste.

Todos esses estudos desenham um panorama da evolução da indústria no Brasil, mostrando as mudanças ocorridas na sua localização espacial. Destaca-se a perda da importância da região Sudeste, em particular Rio de Janeiro e São Paulo, e o aparecimento de novas áreas de concentração industrial nas antigas periferias. Embora seja freqüentemente sugerido que as novas áreas industriais possam constituir aglomerações de empresas especializadas, no sentido considerado neste artigo, os estudos sobre desconcentração industrial não têm como objetivos listar tais configurações ou fazer investigação mais profunda sobre os casos encontrados.

Em trabalhos mais recentes sobre o Brasil, voltados especificamente para a identificação de aglomerações de empresas de menor porte, o método mais difundido e comumente usado, como já mencionado anteriormente, é o IPM. Este método consiste de três etapas. Na primeira etapa são identificadas aglomerações industriais potenciais por meio do quociente locacional (QL). Na segunda etapa são selecionadas as aglomeraçóes industriais preliminares, usando-se critérios específicos. Valores do QL maiores do que hum indicam que há especialização da indústria $i$ na região. Quanto maior o valor do QL a partir de hum, maior é a especialização.

Na primeira etapa, identificação de aglomerações industriais potenciais, o IPM consiste no cálculo do QL. Este coeficiente mede a concentração de emprego numa certa área geográfica e pode ser expresso como:

$$
\mathrm{QL}_{i}=\frac{e_{i} / \sum_{i=1}^{n} e_{i}}{E_{i} / \sum_{i=1}^{n} E_{i}},
$$

em que $e_{i}$ é o emprego na indústria $i$ da região estudada e $E_{i}$ é o emprego nacional da indústria $i$. O coeficiente expressa a participação do emprego regional total da indústria $i$ sobre a participação da indústria $i$ no total do emprego em todas as indústrias. Este coeficiente é calculado para cada uma das $n$ indústrias da região. Quanto maior o QL, maior é a especialização da região.

Embora o cálculo do QL esteja apoiado na hipótese restritiva de que a produtividade localizada do trabalho é igual à produtividade do trabalho num território mais amplo, ele é ainda uma ferramenta bastante útil devido a sua simplicidade. 
A identificação de aglomerações potenciais vai apresentar várias possibilidades a partir do QL. Normalmente é estabelecido um valor fixo para o coeficiente, e são consideradas aglomeraçóes potenciais aquelas que apresentam QL maior que o tal valor fixo. Por exemplo, Britto e Albuquerque (2002), de forma intuitiva, tomam somente os setores de atividade que apresentam QL $>$ l. Puga (2003), no entanto, usa QL $>5$ para a identificação de aglomerações potenciais.

Nota-se que o QL tende a superestimar a existência de aglomerações em pequenas localidades e subestimar nas grandes localidades. Procurando corrigir esta distorção os autores utilizam parâmetros auxiliares. Britto e Albuquerque (2002) usam o QL, mas o calculam com base nas variáveis emprego e remuneração, em vez de estabelecimento. Puga (2003) inclui como variável de controle o número absoluto mínimo de estabelecimentos e trabalhadores.

É claro que as diferenças nos valores fixos do QL e critérios complementares vão gerar divergências sobre o número de aglomerações industriais identificadas pelos coeficientes. Quanto maior o valor fixado, menor será o número de regiões identificadas.

Outra fonte de divergências sobre o número de aglomerações identificadas é o conceito de área geográfica usado nos cálculos. Por exemplo, Britto e Albuquerque (2002) propõem a participação do município em relação ao País; Puga (2003) usa a microrregião em relação ao País; e Suzigan et al. (2003) utilizam microrregião em relação ao Estado.

Dados os QLs, o próximo passo do IPM é agrupar as indústrias individuais em aglomerações industriais preliminares. É comum a utilização de conhecimento geral sobre a indústria e outras informações sobre as regiões. Para selecionar as aglomerações industriais preliminares, Britto e Albuquerque (2002) usam critérios de concentração setorial, diversidade espacial, densidade e complexidade estrutural.

Um refinamento interessante do método de seleção de aglomerações de empresas preliminares é proposto por Suzigan et al. (2003) para o Estado de São Paulo. A partir dos QLs calculados e ordenados aplica-se a fórmula do coeficiente de Gini locacional. ${ }^{6}$ São selecionados os setores de atividade que apresentam Gini locacional positivo. Como o QL e o Gini foram calculados em termos de número de empregos, é possível que um número pequeno de estabelecimentos de grande porte seja selecionado. Para evitar que isto aconteça é feita a checagem do número de estabelecimentos localizados nas áreas onde o QL e o Gini locacional são altos. Puga (2003) utiliza metodologia semelhante, aplicando-a no Brasil, mas estabelece Gini >0,5 para seleção de aglome-

6 Krugman (1991) foi o primeiro autor a utilizar o índice de Gini para medir a concentração espacial de empresas. 
rações potenciais, eliminando aglomerações cujo Gini está entre 0 e 0,5. Com isto, o número de aglomeraçôes identificadas é reduzido.

O Gini locacional complementa com mais rigor o QL, embora seu parâmetro para a seleção de aglomerações possa ser ad hoc, como o QL. Quanto mais alto for o coeficiente, maior a concentração espacial da atividade econômica. O Gini locacional também apresenta a mesma hipótese restritiva do QL sobre a produtividade do trabalho.

O último passo do IPM é o de validação das aglomerações industriais preliminares. Em geral, consiste em pesquisa de campo com empresas e instituições locais. Neste caso, o critério de validação dos vínculos entre as empresas não segue regra específica.

Embora o IPM seja fortemente dependente das opinióes e do conhecimento dos especialistas em economia regional, é ainda a abordagem que melhor se adequa às bases de dados do Brasil. Além disto, estimula a interação entre agentes locais importantes, como instituições governamentais, universidades etc. No entanto, o IPM depende de intuição e/ou heurística na identificação de aglomerações industriais, principalmente no que diz respeito à fixação dos parâmetros para os índices e coeficientes utilizados, e apresenta também dificuldades na comparação entre aglomerações industriais de regióes distintas.

Revisitando o fenômeno da desconcentração industrial, uma terceira abordagem, com metodologia mais elaborada, já é utilizada em alguns estudos sobre o Brasil. Crocco et al. (2003), por exemplo, utilizam técnica de análise multivariada para detectar concentrações de empresas do setor têxtil no País. Para isso os autores desenvolveram um índice de concentração que evita as distorçóes provocadas por valores absolutos do QL. Basicamente, o seu índice de concentração consiste na combinação linear do QL, Hirschman-Herfindahl modificado, participação relativa do setor no emprego total do setor no País. Os pesos específicos desses três indicadores são obtidos por meio da análise de componentes principais. Para detectar autocorrelação espacial da especialização produtiva tem sido utilizada a técnica de econometria espacial denominada Moran Scatterplot. Aplicando a técnica no setor têxtil os autores desenharam um mapa da localização desse setor no Brasil.

Sousa (2002) avança mais neste tipo de metodologia ao investigar variáveis estaduais e industriais que interferem na localização da indústria. Para tanto, ele utiliza o índice de Gini para avaliar concentração industrial, complementado pelo índice de separação espacial de Venables, que leva em consideração a distância entre os Estados. Em seguida é feita análise de componentes principais. Por último, ele aplica um modelo econométrico para determinar os fatores relevantes da localização da indústria. Sua 
análise cobre o período desde a década de 1970. Algumas das conclusões são: a confirmação da tendência de desconcentração, apontada por outros autores, e a maior concentração de setores tecnológicos.

Resende e Wyllie (2005) usam as "medidas de aglomeração" para fazer um estudo empírico sobre a distribuição espacial da indústria no Brasil. Os cálculos são feitos para as microrregióes econômicas e os setores da Classificação Nacional das Atividades Econômicas (CNAE) com a maior desagregação possível. Um dos resultados da pesquisa é que não existe padrão de aglomeração comum aos diferentes setores a quatro dígitos da indústria de transformação.

Esses estudos apoiados em índices de concentração, análise multivariada e aplicação de modelos econométricos são importantes por apontarem medidas mais sólidas de identificação de aglomerações industriais. Entretanto, encontram-se ainda em estágio inicial no Brasil, e provavelmente vão se difundir de forma extensiva no curto prazo.

Não existe consenso sobre o método de identificação e mapeamento de aglomerações em particular em termos das variáveis que devem ser avaliadas. Logo, não somente as interpretações e os termos atribuídos ao objeto variam, mas também os métodos empíricos e as fontes e tipos de dados utilizados. Com isso, há uma variedade de conclusões sobre a quantidade real de aglomerações de empresas no Brasil.

Finalmente, a primeira e a terceira abordagens, em particular, podem indicar onde possíveis aglomerações de empresas estão localizadas, mas não são capazes de capturar a natureza dos vínculos entre empresas, spillovers de conhecimento, redes sociais ou estruturas de apoio institucional que são aspectos especiais atribuídos a essas configurações. Maeda (2003) fez um exercício teórico, baseado na teoria dos jogos cooperativos, que procura averiguar se existem incentivos para as empresas de confecção de Nova Friburgo cooperarem ou não cooperarem para exportar. Muls (2004) fez um exercício para identificar fatores de ordem econômica e extra-econômica, presentes na região de Itaguaí, para explicar a cooperação e, em particular, o acúmulo de capital social. Esses exercícios correspondem, respectivamente, a teses de mestrado e doutorado. Contudo, estes resultados ainda são muito particulares e parciais, servindo apenas como pistas para novos estudos mais abrangentes e mais estruturados que considerem mais fortemente estes fatores e também os aspectos setoriais. Por outro lado, o segundo tipo de análise, o IPM, embora procure capturar tais aspectos especiais, apóia-se mais em hipóteses ad hoc. Na próxima subseção serão mostradas brevemente algumas bases de dados utilizadas nos estudos. 


\section{Bases de Dados Utilizadas}

Além das diferentes metodologias, os autores também utilizam diferentes bases de dados. É intuitivo que diferenças nos resultados entre estudos distintos podem estar relacionadas às diferenças entre fontes e tipos de dados e níveis de agregação desses dados.

Diniz e Crocco (1996), no seu estudo sobre desconcentração industrial, utilizam os censos industriais do Instituto Brasileiro de Geografia e Estatística (IBGE), o Censo Demográfico de 1991 e a Relação Anual de Informações Sociais (RAIS). Pacheco (1999) usa também os censos industriais do IBGE, mas incorpora em sua análise a Pesquisa Industrial Mensal (PIM), também do IBGE, dados sobre intenções de investimentos do Ministério da Indústria e dados do Cadastro Geral de Empregados e Desempregados (CAGED) e da RAIS. Sousa (2002), assim como os outros, utiliza os censos industriais do IBGE, mas acrescenta ao estudo dados da Pesquisa Industrial Anual (PIA).

Devido às dificuldades apresentadas por várias fontes de dados, ${ }^{7}$ grande parte dos estudos depende dos dados da RAIS. De acordo com Suzigan et al. (2003), a principal vantagem da RAIS é o nível detalhado de desagregação geográfica e setorial dos dados. Por outro lado, existem algumas deficiências da metodologia de coleta de dados, quais sejam: a cobertura apenas de relações formais de trabalho e a autoclassificação das empresas na coleta das informações. Contudo, a RAIS ainda é apropriada tanto para estudos com análise multivariada e econometria como estudos de desconcentração espacial com utilização do IPM.

De forma geral, os estudos principalmente do tipo "top-down" têm que se ajustar a dados sobre produto, emprego, estabelecimentos etc. coletados e organizados de acordo com o padrão de classificação dos setores da indústria, CNAE. Os dados vêm de pesquisas feitas em unidades políticas e administrativas preestabelecidas, como Estados, municípios, microrregiões etc., que podem não coincidir com a fronteira da configuração que está sendo analisada. Finalmente, essas análises são difíceis de conciliar com as demais bases estatísticas brasileiras que não abrangem empresas de menor porte em detalhe, como o faz a base de dados RAIS.

Uma forma alternativa é a identificação direta de aglomerações de empresas por meio de consulta às autoridades locais, diminuindo o peso das estatísticas secundárias na pesquisa. O risco neste caso é associar a identificação dessas configurações às aspirações políticas locais. (Martin e Sunley, 2003).

7 Uma discussão detalhada sobre esse assunto é feita por Resende e Wyllie (2005). 


\section{MÉTODOS DE CLASSIFICAÇÃO UTILIZADOS NOS ESTUDOS SOBRE DESENVOLVIMENTO ECONOAMICO LOCAL}

A criação de classificações e tipologias é um estágio importante de teorização e análise. Para ter significado em desenvolvimentos teóricos as tipologias devem vir de estudos comparativos profundos sobre características empíricas e processos das aglomerações de empresas. A tipologia proposta por Markusen (1994) é um bom exemplo dentro desse espírito, comentada a seguir.

A autora não estava tão convencida da possibilidade das PMEs se auto-organizarem em um regime de produção flexível. Ela acreditava fortemente no poder hierárquico das instituições e do governo, via provimento de infra-estruturas, e das grandes empresas no estabelecimento de trajetórias industriais nas regiões. Desta forma criou uma taxonomia, a partir dos padrões encontrados em seus vários estudos empíricos, composta de quatro tipos morfológicos: aglomeração marshaliana ou italiana; aglomeração centro radial; aglomeração plataforma satélite; e aglomeração suportada pelo governo ou por importantes instituições.

As principais características do primeiro tipo morfológico são grande grupo de PMEs controladas localmente, redes de cooperação, intensas relações e expressivas economias externas. Entre as principais características do segundo tipo morfológico destacam-se: uma estrutura produtiva regional de PMEs que gira em torno de uma ou mais grandes corporações, e atração de fornecedores especializados, que aumentam a especialização regional. As corporações de maior porte são as firmas líderes que estabelecem as relações da aglomeração centro radial com o exterior. O terceiro tipo morfológico, plataforma satélite, é uma aglomeração formada principalmente por filiais de empresas multinacionais ou grandes corporações que para ali se deslocaram por terem sido atraídas por baixos salários ou subsídios oferecidos pela localidade. Elas possuem fracas vinculações locais, e as suas empresas matrizes - em geral o centro decisório dessas empresas - estão localizadas fora do sítio. Finalmente, o quarto tipo morfológico, aglomeração induzida pelo governo ou por importantes instituições, resulta de efeitos de spin offs de pesquisas e conhecimentos realizados nos centros de pesquisa e de universidades ou de grandes projetos governamentais que, por meio de infra-estrutura especializada, criam condições para uma localização industrial privilegiada.

No Brasil já existem alguns estudos empíricos que procuram fazer classificações ou introduzir tipologias. A Redesist, por exemplo, realizou estudos em 26 arranjos e sistemas produtivos locais a partir de 1998. Baseados nesses estudos, Cassiolato e Szapiro (2003) propóem uma taxonomia, apresentada no Quadro 1. 


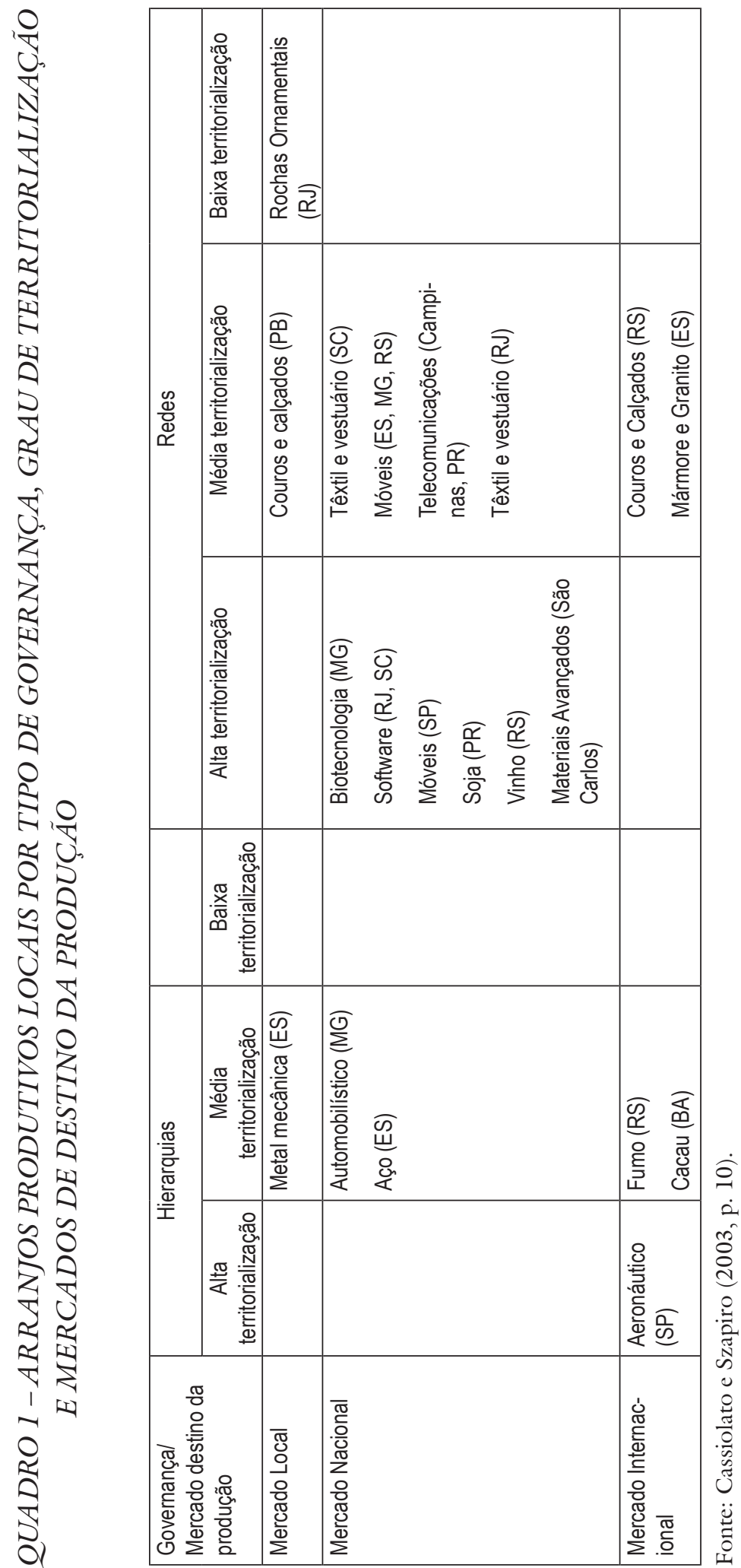

Estud. econ., São Paulo, 36(3): 407-433, jul-set 2006 
No entanto, a proposição desta taxonomia é muito mais descritiva, constatando apenas os fatos estilizados identificados em cada caso, do que analítica e explicativa de cada um dos casos. Enquadram na mesma classificação categorias muito distintas de setores industriais tais como o de telecomunicações com móveis, têxtil e vestuário. A coordenação e governança considerados elementos importantes para explicar características e processos em aglomerações de empresas, como a presença de cooperação, não são abordados. As hierarquias e as redes são classificadas apenas em função da territorialização. Ainda que este seja um aspecto importante e reconhecido pela maioria dos autores que estudam o tema, deixa de fora outros fatores explicativos mais importantes na formação de hierarquias e redes, tais como os interesses econômicos dos agentes e os interesses extra-econômicos.

O trabalho de Suzigan et al. (2003) se destaca entre os consultados por ser um passo importante na criação de uma metodologia de classificação útil para a seleção de aglomerações de empresas que posteriormente deveriam ser objeto de estudos de caso. Os autores adotam o conceito de SLP, discutido na seção 2 deste artigo, e caracterizam quatro tipos básicos de SLPs, a partir do uso dessa metodologia:

1) Núcleos de desenvolvimento setorial-regional são SLPs que se destacam duplamente: pela sua enorme importância para uma região e para o setor de atividade econômica em torno do qual as suas atividades estão nucleadas.

2) Vetores avançados possuem grande importância para o setor (traduzida na sua participação na produção e no emprego), mas estão diluídos num tecido econômico muito maior e mais diversificado; ou seja, eles são importantes para o setor, mas o desenvolvimento econômico regional não depende deles de uma forma tão pronunciada.

3) Vetores de desenvolvimento local são importantes para uma região, embora não possuam uma contribuição decisiva para o setor principal a que estão vinculados.

4) Embriões de arranjo produtivo são SLPs que possuem pouca importância para o seu setor e convivem, na região, com outras atividades econômicas. (Suzigan et al., 2003, p. 12).

Embora a taxonomia construída seja restrita aos casos do Estado de São Paulo, este trabalho procura classificar tais casos e alinhá-los aos tipos de SLPs propostos. O Quadro 2 ilustra esta tentativa. 
QUADRO 2 - TIPOLOGIA E EXEMPLOS DE SLPS NO ESTADO DE SÃO PAULO

\begin{tabular}{|l|l|l|}
\hline \multirow{2}{*}{ Importância Local } & \multicolumn{2}{|c|}{ Importância para o Setor } \\
\cline { 2 - 3 } & \multicolumn{1}{|c|}{ Reduzida } & \multicolumn{1}{|c|}{ Elevada } \\
\hline Elevada & $\begin{array}{l}\text { Dracena - cerâmica; Campos de Jordão } \\
\text { - confecção; Jaú - calçados; Amparo } \\
\text { - confecções; São José do Rio Preto } \\
\text { - jóias }\end{array}$ & $\begin{array}{l}\text { Franca - calçados; Limeira - jóias; Birigui } \\
\text { - calçados; Ribeirão Preto - equipamentos } \\
\text { médicos; Araraquara - artefatos têxteis }\end{array}$ \\
\hline Reduzida & $\begin{array}{l}\text { Ourinhos - calçados; Pirassununga } \\
\text { - cerâmica; Limeira - máquina ferramenta; } \\
\text { Mogi-Mirim - cerâmica; Ribeirão Preto } \\
\text { - máquinas agricolas }\end{array}$ & $\begin{array}{l}\text { Campinas - têxtil, telecomunicações e } \\
\text { equipamentos óticos; São Paulo - vestuário, } \\
\text { equipamentos médicos e materiais eletrônicos }\end{array}$ \\
\hline
\end{tabular}

Fonte: Suzigan et al. (2003, p. 13).

A idéia dessa taxonomia é permitir a aplicação de política industrial mais focada conforme as características identificadas acima. Assim, para os SLPs do primeiro tipo, SLPs com uma história e tradições industriais longas, mas uma dependência comercial forte, propugna-se uma superação da dependência dos canais e nas formas de comercialização, entre outras medidas; para os SLPs do tipo embrião, a identificação de núcleos de mercado para impedir a competição predatória por preços.

Alguns organismos formuladores de políticas brasileiros têm tido interesse em compreender melhor estes processos de desenvolvimento industrial localizado com o objetivo de formular políticas reprodutivas destes casos de sucesso. ${ }^{8}$ Este é o caso do Instituto de Pesquisa Econômica Aplicada - IPEA, que estuda desde 1996 esta temática e realizou um estudo sobre o tema publicado no livro organizado por Tironi (2001), onde o organizador, além de propor uma metodologia abrangente sobre o tema, apresenta o estudo de 11 casos, nas mais distantes regiões brasileiras, com especializações produtivas distintas, realizado por equipes pertencentes a vários centros de pesquisa.

O Serviço de Apoio à Micro e Pequena Empresas no Brasil - SEBRAE, o Instituto de Estudos para o Desenvolvimento Industrial - IEDI e o Banco Nacional de

8 É importante ressaltar também a criação do Grupo de Trabalho Permanente para Arranjos Produtivos Locais, no âmbito do Ministério do Desenvolvimento, Indústria e Comércio Exterior, em agosto de 2004, por meio da Portaria Interministerial $\mathrm{n}^{\circ} 200$. O objetivo é promover a complementaridade das ações das entidades ofertantes no apoio a APLs, 22 entidades governamentais e não-governamentais, sob a coordenação do MDIC. Até agora esta ação se restringiu a eleger 11 APLs pilotos com o propósito de testar a metodologia de ação integrada. 
Desenvolvimento Econômico e Social - BNDES também são órgãos de fomento à indústria que têm se preocupado em realizar diagnósticos e propor medidas de apoio.

No entanto, com tantas possibilidades de definição, identificação e classificação não ficam claras quais seriam as políticas industriais mais adequadas para as aglomerações de empresas. Para isso é necessário o aprofundamento dos estudos empíricos e desenvolvimento de teorias mais específicas para o fenômeno.

\section{COMENTÁRIOS FINAIS}

O interesse deste artigo foi focalizar as diferentes metodologias utilizadas em estudos de desenvolvimento econômico local sobre o Brasil. Foi dada ênfase ao enfoque amplo e múltiplo utilizado por grupos de pesquisa distintos e às dificuldades que isto traz para o estabelecimento de comparações entre os vários estudos empíricos já realizados.

Observa-se que a maioria dos estudos enfatiza a existência de uma especialização produtiva dominante mesmo que as micro e pequenas empresas apresentem poucas ligações entre si. As diferenças entre esses estudos iniciam-se nas próprias definições e termos utilizados. Se o regime de produção fordista tornou-se obsoleto, o regime de produção flexível ou o modelo de distritos industriais não captura, necessariamente, a realidade das aglomerações brasileiras. Isto ocorre porque os modelos por meio dos quais os autores mais influentes da comunidade acadêmica caracterizam as manifestações da industrialização flexível ou descentralização vêm de construções estilizadas muito distantes da realidade no Brasil. Logo, uma das principais liçôes deste artigo é que antes de se tomar abstrações baseadas em realidades distintas da brasileira seria importante aprofundar o conhecimento empírico sobre as características deste país.

Se este procedimento for adotado, será observado que as metodologias quantitativas têm sido aplicadas, mas não há consenso entre as escalas territoriais e produtivas adotadas. Há carência de metodologias para identificar as interações entre empresas, e entre estas e as instituições, e para avaliar a densidade e as características de tais interações. Os estudos brasileiros indicam níveis indiscutíveis de especialização e de concentração espacial. Mas, como não há consenso sobre as metodologias adotadas, as conclusões divergem de um estudo para outro.

A justificativa para avançar neste sentido é, por um lado, reduzir a dificuldade para identificar novos focos de política e os objetos que deverão ser os seus alvos. Por outro lado, a infinidade de metodologias, fontes estatísticas deficientes e formas de tratamento dos dados é um conjunto de características comum em novas áreas de conhecimento, mas o seu avanço e maturidade deveriam pelo menos caminhar para algumas linhas de convergência entre diversas escolas concorrentes. No entanto, o 
que é mais grave é o reflexo dessa infinidade de metodologias na definição de política econômica, dificultando a estruturação e o desenho institucional de uma política mais abrangente. ${ }^{9}$

É consensual, entretanto, entre os estudos, a importância crescente das empresas de tamanho pequeno e médio nas novas configurações industriais. Mas a ausência de conhecimento suficiente da realidade empresarial brasileira leva vários autores a idealizarem essas empresas em termos do seu alcance de desenvolvimento econômico. Muitos pensam que somente a existência de um apoio de qualquer natureza é suficiente para ativar o desenvolvimento e a competitividade dessas empresas.

Outros autores têm consciência que as pequenas e médias empresas necessitam cooperar para obter resultados econômicos mais eficazes. Mas os métodos utilizados para avaliar a intensidade da cooperação dividem esses autores, não havendo clareza, às vezes, sobre as diferenças entre cadeias produtivas e clusters. Outros, enfim, pensam simplesmente que as relações técnicas animadas por motivações econômicas são capazes de provocar o aparecimento dos tipos ideais de distrito industrial, sistema produtivo local ou cluster, mesmo que outros estudos sublinhem a importância da dimensão institucional no desenvolvimento e na consolidação das aglomerações.

É possível que a implementação de políticas inadequadas ao contexto brasileiro, devido à falta de conhecimento sobre o conteúdo das relações entre as empresas, provoque $\mathrm{o}$ atraso no seu desenvolvimento pleno. A falta de nitidez sobre o papel das instituiçôes de apoio e das políticas econômicas propostas pode levar os empresários à formação de expectativas equivocadas sobre a atuação dessas instituições e políticas. A frustração de tais expectativas pode ferir a credibilidade dessas instituições, tornando o processo de implementação de políticas de desenvolvimento ainda mais complexo.

\section{BIBLIOGRAFIA}

Altenburg, T.; Meyer-Stamer, J. How to promote clusters: policy experiences from Latin America. World Development, v. 27, n. 9, p. 1693-1713, 1999.

Andrade, T. A.; Serra, R. V. (orgs.). Cidades médias brasileiras. Rio de Janeiro: IPEA, 2001.

Bazan, L.; Schmitz, H. Social capital and export growth: an industrial community in Southern Brazil. Discussion Paper IDS, n. 361, august 1997.

9 Estamos nos referindo aqui à dificuldade de ampliação da atual seleção de 11 APLs piloto para um conjunto mais abrangente, conforme explicado na nota de rodapé anterior. 
Becattini, G. Dal settore industriale al distretto industriale: alcune considerazioni sull'unità d'indagine dell'economia industriale". Rivista di Economia e Politica Industriale, n. 1, 1979.

. The Marshallian industrial district as a socio-economic notion. In: Pyke, F. et al. (orgs.), Industrial districts and inter-firm cooperation in Italy. Geneva: International Institute for Labour Studies, 1990.

Belussi, F.; Gottard G. (eds.). Evolutionary patterns of local industrial systems: towards a cognitive approach to the industrial district. Ashgate Publishing Ltd, 2000.

Bourdieu, P. The forms of capital. In: Richardson, J. G. (org.), Handbook of theory and research in the sociology of education. New York: Greenwald Press, 1986.

Britto, J.; Albuquerque, E. M. Chusters industriais na economia brasileira: uma análise exploratória a partir de dados da RAIS. Estudos Econômicos, São Paulo, v. 32, n. 1, p. 71-102, jan./mar. 2002.

Carlsson, B.; Eliasson, G. Industrial dynamics and endogenous growth. Industry and Innovation, v. 10, n. 4, p. 435-455, dez. 2003.

Cassiolato, J. E.; Lastres, H. M. M. O foco em arranjos produtivos e inovativos locais de micro e pequenas empresas. In: Lastres, H. M. M.; Cassiolato, J. E.; Maciel, M. L. (orgs.), Pequenas empresas: cooperação e desenvolvimento local. Relume Dumará Editora, Capítulo 1, julho 2003.

Cassiolato, J. E.; Szapiro, M. Uma caracterização de arranjos produtivos locais de micro e pequenas empresas. In: Lastres, H. M. M.; Cassiolato, J. E.; Maciel, M. L. (orgs), Pequenas empresas: cooperação e desenvolvimento local. Relume Dumará Editora, Capítulo 2, julho, 2003.

Coleman, J. S. Foundations of social theory. Cambridge, MA: University Press, 1990.

Crocco, M. A.; Rangel, G.; Santos, F.; Lemos, M. B.; Simões, R. Metodologia de identificação de arranjos produtivos potenciais. Texto para Discussão. Belo Horizonte: CEDEPLAR, 2003.

Diniz, C. C.; Crocco, M. A. Reestruturação econômica e impacto regional: o novo mapa da indústria brasileira. Nova Economia, Belo Horizonte, v. 6, n. 1, p. 77103, julho 1996.

Fauré, Y. A.; Hasenclever, L. O desenvolvimento econômico local no Estado do Rio de Janeiro. Quatro estudos exploratórios: Campos, Itaguaí, Macaé e Nova Friburgo. Rio de Janeiro: E-Papers Serviços Editoriais, 2003.

. O desenvolvimento local no Estado do Rio de Janeiro: estudos avançados nas realidades municipais. Rio de Janeiro: E-Papers Serviços Editoriais, 2005.

Galvão, C. A. Sistemas industriais localizados: o Vale do Paranhana - complexo calçadista do Rio Grande do Sul. Texto para Discussão IPEA, n. 617, janeiro de 1999.

Granovetter, M. Economic action and social structure: the problem of embeddedness. American Journal of Sociology, n. 91, p. 481-510, 1985. 
Gentler, M. Tacit knowledge and the economic geography, or the indefinable tacitness of being (there). Journal of Economic Geography, v. 3, n. 1, p. 75-99, 2003.

Krugman, P. Geography and trade. Cambridge: MIT Press, 1991.

Lins, H. N. Reestruturação industrial em Santa Catarina: pequenas e médias empresas têxteis vestuaristas catarinenses perante os desafios dos anos 90. Florianópolis, SC: Editora UFSC, 2000.

. Clusters industriais, competitividade e desenvolvimento regional: da experiência à necessidade de promoção. Estudos Econômicos, v. 30, n. 2, p. 233-265, abr./jun. 2000.

Lombardi, M. The cognitive approach to the study of local production systems. In: Belussi, F; Gottard, G. (eds), Evolutionary patterns of local industrial systems: towards a cognitive approach to the industrial district. Ashgate, 2000.

Maeda, I. Análise do mercado de compra e venda de Nova Friburgo sob o enfoque da teoria dos jogos cooperativa. 2003. Dissertação (Mestrado), Rio de Janeiro: IE/UFRJ.

Markusen, A. R. et al. Sticky places in slippery space: the political economy of postwar fast growth regions. Rutgers University, Working Paper 79, 1994.

Marshall, A. Principles of economics. $8^{\mathrm{a}}$ edição. London: Macmillan and Co. Ltd., 1920.

Marteleto, R. M.; Silva, A. B. O. Redes e capital social: o enfoque da informação para o desenvolvimento local. Ciência e Informação, Brasília, v. 33, n. 3, p. 4149, set./dez. 2004.

Martin, R.; Sunley, P. Deconstructing clusters: chaotic concept or policy panacea? Journal of Economic Geography, v. 3, n. 1, p. 5-35, 2003.

Muls, L. Capital social, MPMEs e desenvolvimento econômico no município de Itaguai: as micro, pequenas e médias empresas, o Projeto do Porto de Sepetiba e o ambiente institucional. 2004. Tese (Doutorado), Rio de Janeiro: IE/UFRJ.

Pacheco, C. A. Novos padrões de localização industrial? Tendências recentes dos indicadores da produção e do investimento industrial. Texto para Discussão IPEA, n. 633, março de 1999.

Piore, M. J.; Sabel, C. F. The second industrial divide: possibilities for prosperity. New York: Basic Books, 1984.

Puga, F. P. Alternativas de apoio a MPMEs localizadas em arranjos produtivos locais. Texto para Discussão, n. 99, Rio de Janeiro: BNDES, junho 2003.

Putnam, R. D. Making democracy work. Civic traditions in modern Italy. Princeton, NJ: Princeton University Press, 1993.

Raud, C. Indústria, território e meio ambiente no Brasil: perspectiva da industrialização descentralizada a partir da análise da experiência catarinense. Florianópolis: Ed. UFSC; Blumenau: Editora da FURB, 1999. 
Resende M.; Wyllie, R. Aglomeração industrial no Brasil: um estudo empírico. Estudos Econômicos, São Paulo, v. 35, n. 3, p. 433-460, jul./set. 2005.

Saboia, J. L. Desconcentração industrial no Brasil nos anos 90: um enfoque regional. Pesquisa e Planejamento Econômico, 30, p. 69-116, 2000.

SEBRAE. Caracterização e análise de arranjos produtivos locais no Estado do Rio de Janeiro. Rio de Janeiro, outubro 2003.

Scott, A. J. Flexible production systems and regional development: the rise of new industrial space in North America and Western Europe. IJURR, v. 12, n. 2, 1988.

Schmitz, H. Growth constraints on small-scale manufacturing in developing countries: a critical review. World Development, v. 10, n. 6, 1982.

. Small shoemakers and fordist giants: tale of a supercluster. World Development, v. 23, n. 1, p. 9-28, 1995.

Schmitz, H.; Nadvi, K. Clustering and industrialisation: introduction. World Development, v. 27, n. 9, p. 1503-1514, 1999.

Santos, F.; Crocco, M.; Lemos, M. B. Arranjos e sistemas produtivos locais em "espaços industriais" periféricos: estudo comparativo de dois casos brasileiros. Revista de Economia Contemporánea, v. 6, n. 2, 2002.

Sousa, F. L. A localização da indústria de transformação brasileira nas últimas três décadas. Texto para Discussão, n. 95, Rio de Janeiro: BNDES, agosto 2002.

Stevens, C. The knowledge-driven economy. In: The knowledge economy. Boston: Ed. D. Neef, Butterworth-Heinemann, 1998.

Storper, M. The transition to flexible specialization in industry, external economies, the division of labor and the crossing industrial divides. Cambridge Journal of Economics, v. 13, 1989.

Suzigan, W.; Furtado, J. Garcia; Sampaio, S. Sistemas locais de produção: mapeamento, tipologia e sugestóes de políticas. Encontro Nacional de Economia, ANPEC, 2003.

. Local production and innovation systems in the State of São Paulo, Brazil. The $43^{\text {rd }}$ European Congress of the Regional Science Association, Jyvaskyla, Filand: ERSA, 27-30 August, 2003.

Tironi, L. (coord.). Industrialização descentralizada: sistemas industriais locais. Brasília: IPEA, 2001.

Vargas, M. A. Forms of governance, learning mechanism and upgrading strategies in the tobacco cluster in Rio Pardo Valley - Brazil. IDS Working Paper, University of Sussex, n. 125, 2001. 